\title{
INTERRELATIONSHIP AND SPILLOVER EFFECT BETWEEN STOCK AND EXCHANGE RATE MARKETS IN THE MAJOR EMERGING ECONOMIES
}

\section{Jovan Njegić, Dejan Živkov, Irena Janković*}

\begin{abstract}
This paper analyses the dynamic nexus and bidirectional spillover effect between stocks and exchange rates in seven major emerging markets and one developed market. Three types of BEKKGARCH models were utilized in the research process - basic BEKK-GARCH, asymmetric BEKK-GARCH and asymmetric BEKK-GARCH with structural breaks. Model with breaks gave the best fitting results in six out of eight cases. VAR based volatility spillover method serves as a complementary methodology. Results showed that dynamic connection between two major asset classes behaves in accordance with the portfolio balanced approach in emerging markets, while the nexus is in line with the flow oriented theory in the US market. In addition, according to the BEKK-GARCH results, shock and volatility spillover effect is predominantly directed from exchange rate market to stock market in all countries, while in the VAR based model it is not so obvious.
\end{abstract}

Keywords: stocks, exchange rate, BEKK-GARCH, structural breaks

JEL Classification: C51, F31, G15

\section{Introduction}

Many international investors have decided to invest in emerging markets in the last two decades, due to the fast and robust growth, capital liberalization and overall reform process that these markets commenced, as shown by Coudert et al. (2011), Hanousek and Kočenda (2011), Durčáková (2011). However, realized returns on emerging stock markets expressed in some solid currency (e.g. $\$, €, ¥, £, F)$, could be jeopardized due to unstable domestic exchange rates. Thus, many international investors and portfolio managers endeavour to understand the mutual interrelationship between the two major financial assets - foreign exchange and stocks. Two theoretical tenets in the international finance try to offer an explanation for the interconnection between these assets - the flow oriented model and the portfolio-balance approach. The flow-oriented model propounds that appreciation (depreciation) of domestic currency decreases (increases) international competitiveness, which eventually has an influence on the balance of trade position as well as firm's cash flow, leading to the fall (rise) of stock prices. This approach focuses on the country's current account, advocating positive correlation between the two assets.

* Jovan Njegic, Business School of Novi Sad, University of Novi Sad, Serbia (jovan.nj@gmail.com); Dejan Živkov, Business School of Novi Sad, University of Novi Sad, Serbia (dejanzivkov@gmail.com); Irena Jankovic, Faculty of Economics, University of Belgrade, Serbia (irenaj@ekof.bg.ac.rs). 
On the other hand, the portfolio-balance theory underlines capital inflow (outflow) which affects demand and supply for domestic stocks, as well as national currency. This approach has shown that currency depreciation will induce lower demand for domestic stocks, causing their lower value, while currency appreciation will induce the opposite effect. According to this hypothesis, the nexus between stocks and exchange rates is described by negative correlation coefficient. Some recent studies explored interconnection between stocks and exchange rates in developed and emerging markets - Tsagkanos and Siriopoulos (2013), Alagidede et al. (2011) and Živkov et al. (2016). In addition, it is common knowledge that the two major national financial markets are integrated and intertwined to some extent, so it undoubtedly raises a question - what is the level of shock spillover between stock and exchange rate markets, and which market has higher shock transmission influence on the other one? Following papers, inter alia, dealt with this issue - Caporale et al. (2014), Yau and Nieh (2009) and Inci and Lee (2014).

Therefore, the objective of this paper is two-fold. Firstly, we have tried to explore the dynamic nexus between exchange rate and stock returns in short run in seven major Eurasian emerging economies that conduct flexible exchange rate policy. Secondly, we have strived to gauge the intensity of bidirectional spillover effect between the two major financial markets in these countries. The selection of countries is made based on the level of GDP, i.e. we choose three biggest Eastern European economies and four biggest countries of continental Asia. The following countries have been analysed: the Czech Republic, Poland, Hungary, Russia, Turkey, India and South Korea. The observed timespan covers 16 and a half years. Besides, for the purpose of comparison we also analyse the largest world economy - the USA. Hungary conducts fixed exchange rate regime with wide bands, while Russia applied tight management till 2008 and greater exchange rate flexibility afterwards. All the other countries pursue de jure and de facto flexible exchange rate regimes. For the research purposes, we have utilized three types of bivariate BEKKGARCH methodology: the ordinary BEKK-GARCH model, asymmetric BEKK-GARCH and asymmetric BEKK-GARCH with structural breaks. To the best of our knowledge, this is the first time that stocks-exchange rate nexus is analysed via the A-BEKK-GARCH model with structural breaks inclusion. These particular models are capable of generating dynamic correlation as well as measuring the spillover effect between observed assets. By using three different BEKK-GARCH specifications we have tried to upgrade the results obtained by implementing basic BEKK-GARCH model in terms of their reliability and accuracy. Several reasons justify this approach. First of all, asymmetric BEKK-GARCH is able to investigate the asymmetric responses of conditional volatility to negative shocks. Furthermore, some authors claimed that if structural breaks are overlooked in variance it could cause multiple specification biases. Hillebrand (2005), Kramer and Azamo (2007) in particular asserted that volatility persistence might be overestimated and heavily inclined towards one if deterministic regime shifts are ignored in GARCH models. Some papers as Ewing and Malik (2005), Huang (2012), and Jung and Maderitsch (2014) documented that volatility spillover effect could be biased if structural shifts are not recognized in the models. In addition, Miralles-Marcelo et al. (2008) found that asymmetric effect in the GARCH framework could be wrongly assessed 
if structural breaks are not taken into account. All these contentions are tested in Section 4. In order to verify the BEKK-GARCH results, we have used additionally a complementary methodology - generalized VAR (GVAR) methodology of Diebold and Yilmaz (2012).

Beside introduction, the paper is organized as follows. Section 2 explains utilized methodology. Dataset and multiple structural breaks are presented in Section 3 while Section 4 contains empirical results. Section 5 offers conclusion.

\section{Methodology}

\subsection{BEKK-GARCH models}

This section contains the theoretical explanations of various full BEKK-GARCH models, namely: the ordinary full BEKK-GARCH model, the asymmetric full BEKK-GARCH model and the asymmetric full BEKK-GARCH model with dummy variables. Initially, Engle and Kroner (1995) proposed the multivariate BEKK-GARCH parameterization which guarantees the positive semi-definiteness of the matrix $\mathbf{H}_{t}$ that depends on the squares and cross-products of the error terms $\varepsilon_{t}$ and volatility. The full BEKK-GARCH model particularly provides a crossmarket shock and volatility effects in the conditional variance equation. For every multivariate full BEKK-GARCH model we considered AR(1) specification in the mean equation as follows:

$$
\boldsymbol{y}_{i, t}=c_{i}+\Phi_{i} A R_{i, t-1}+\varepsilon_{i, t} ; \quad \varepsilon_{i, t} \sim i i d,
$$

where $\boldsymbol{y}_{i, t}$ is the $2 \times 1$ vector $\boldsymbol{y}_{i, t}=\left[r_{i, t}, e_{i, t}\right]^{\prime}$ containing the returns of particular stock index $(r)$ and national foreign exchange rate $(e)$ of selected country $(i)$ at time $t$. All stock returns are calculated as $r_{i, t}=100 \times \log \left(P_{i, t} / P_{i, t-1}\right)$, where $P_{i, t}$ is the closing price, whereas $e_{i, t}=100 \mathrm{x} \log$ $\left(F X_{i, t} / F X_{i, t-1}\right)$ is exchange rate change and $F X$ is nominal exchange rate of particular currency observed vis-à-vis euro. Label $\Phi$ is parameter of the first autoregressive term. Symbol $\varepsilon_{t}$ stands for a series of independently and identically distributed error terms of selected stock indices, for which it is assumed to follow the standard Student-t distribution due to the fact that residual distributions of selected daily asset returns commonly tend to report asymmetry and leptokurtosis.

Basic BEKK-GARCH specification can be characterized by the following expressions:

$$
\mathbf{H}_{t}=\omega^{\prime} \omega+\mathbf{A}^{\prime} \varepsilon_{t-1} \varepsilon_{t-1}^{\prime} \mathbf{A}+\mathbf{B}^{\prime} \mathbf{H}_{t-1} \mathbf{B}
$$

where $\mathbf{H}_{t}$ represents a $2 \times 2$ matrix of conditional variance-covariance at time $t$, and $\boldsymbol{\omega}$ is a $2 \times 2$ lower triangular matrix of constants with three parameters. Symbol A represents a $2 \times 2$ square matrix of parameters and measures the extent to which conditional variances are correlated with past squared errors. Statistically significant diagonal parameters $a_{11}$ and $a_{22}$ in matrix A capture their own ARCH effect indicating that conditional variances are affected by past squared errors, while statistically significant diagonal elements $b_{11}$ and $b_{22}$ in matrix $\mathbf{B}$ gauge their own GARCH effect suggesting that current conditional variance is affected by their own past conditional volatility. The off-diagonal parameters $\left(a_{12}, a_{21}\right.$ and $\left.b_{12}, b_{21}\right)$ in matrices $\mathbf{A}$ and $\mathbf{B}$ disclose the manner in which shock and volatility are transmitted over time and across the selected financial markets. 
Kroner and $\mathrm{Ng}$ (1998) propounded an extension of the Equation 1 with an aim to investigate the asymmetric responses of conditional volatility to negative shocks. This specification allows to measure whether negative shock (bad news) commands higher conditional variance than positive shock (good news). As Carpantier and Samkharadze (2013) asserted, the asymmetric BEKK-GARCH model is a multivariate transposition of the univariate GJR-GARCH model. The asymmetric full BEKK-GARCH model has the following form of the matrix $\mathbf{H}_{\boldsymbol{t}}$ :

$$
\mathbf{H}_{t}=\omega^{\prime} \omega+\mathbf{A}^{\prime} \varepsilon_{t-1} \varepsilon_{t-1}^{\prime} \mathbf{A}+\mathbf{B}^{\prime} \mathbf{H}_{t-1} \mathbf{B}+\mathbf{C}^{\prime} \eta_{t-1} \eta_{t-1}^{\prime} \mathbf{C},
$$

where $\mathbf{C}$ is a $2 \times 2$ matrix that measures asymmetric ARCH effects, indicating that negative shock (bad news) has higher effect on conditional variance than positive shock (good news), where $\eta_{t-1}=\varepsilon_{t-1} I ; I=0\left|\varepsilon_{t}>0 \vee I=1\right| \varepsilon_{t} \leq 0$. The diagonal coefficients $c_{11}$ and $c_{22}$ of the matrix $\mathbf{C}$ gauge the responses of its own negative shocks of return series on its current conditional volatility, whereas off-diagonal elements $c_{12}$ and $c_{21}$ of the matrix measure the shock and volatility spillovers between return series.

In order to further upgrade and ameliorate the BEKK-GARCH specification, we refer to Gannon and Au-Yeung (2004), Kang et al. (2011), Miralles-Marcelo et al. (2013) who augmented basic BEKK-GARCH model by adding a set of dichotomous variables into the conditional variance-covariance matrix, in order to capture regime changes in variances. The break points are endogenously identified by the modified ICSS algorithm of Sansó et al. (2004). In accordance with this, the conditional variance-covariance matrix of the A-BEKK-GARCH model with implemented dummy variables can be presented as:

$$
\mathbf{H}_{t}=\omega^{\prime} \omega+\mathbf{A}^{\prime} \varepsilon_{t-1} \varepsilon_{t-1}^{\prime} \mathbf{A}+\mathbf{B}^{\prime} \mathbf{H}_{t-1} \mathbf{B}+\mathbf{C}^{\prime} \varepsilon_{t-1} \varepsilon_{t-1}^{\prime} \mathbf{C}+\sum_{i=1}^{n} \mathbf{D}_{i}^{\prime} \mathbf{X}_{i}^{\prime} \mathbf{X}_{i} \mathbf{D}_{i},
$$

where symbol $\mathbf{D}_{i}$ stands for a $2 \times 2$ square diagonal matrix of parameters and $\mathbf{X}_{i}$ is a $1 \times 2$ row vector of volatility regime control variables, while $n$ represents the number of sudden change points found in variance of index and exchange rate series. This model produces additional two parameters $\left(d_{1}\right.$ and $\left.d_{2}\right)$, which statistical significance indicates the relevance of inserted dummy variables.

All BEKK-GARCH models are estimated by the quasi-maximum likelihood (QMLE) technique, which is also known as Berndt-Hall-Hall-Hausman (BHHH) routine. This procedure allows for asymptotically consistent parameter estimates, even if the underlying distribution is not normal, as contended by Bollerslev and Wooldridge (1992).

\subsection{Modified ICSS algorithm}

In order to detect multiple structural breaks in unconditional variance of selected assets, we opt for modified ICSS algorithm of Sansó et al. (2004). Initially, Inclan and Tiao (1994), hereafter referred to as IT, developed basic ICSS procedure, assuming that variance of a time series is stationary over an initial period of time, until a sudden jump occurs. However, this assumption is a highly unlikely characteristics for financial series in which dependent GARCH process is present. Thus, the study of Sans'o et al. (2004) showed that IT process 
can be significantly oversized due to the presence of heavy-tails, where extreme values could be recognized as points of structural breaks, even though they should be classified as outliers. As a result, Sansó et al. (2004) proposed a new test, modified ICSS, which explicitly takes into account the fourth moment properties of the time series, avoiding the exaggeration of detected sudden jumps. Following some recent studies of Mensi et al. (2014), Vivian and Wohar (2012), Živkov et al. (2015) and Mensi et al. (2015) who utilized modified ICSS algorithm (MIT) in empirical log-returns series, we applied exact non-parametric adjustment based on the Bartlett kernel, which is set as:

where

$$
M I T=\sup _{k}\left|T^{-0.5} G_{k}\right|,
$$

$G_{k}=\hat{\lambda}^{-0.5}\left[C_{k}-(k / T) C_{T}\right] ; \hat{\lambda}=\hat{\gamma}_{0}+2 \sum_{l=1}^{m}\left[1-l(m+1)^{-1}\right] \hat{\gamma}_{l} ; \hat{\gamma}_{l}=T^{-1} \sum_{t=l+1}^{T}\left(\tau_{t}^{2}-\hat{\sigma}^{2}\right)\left(\tau_{t-1}^{2}-\hat{\sigma}^{2}\right) ;$

$\hat{\sigma}^{2}=T^{-1} C_{T}$. According to the procedure of Newey and West (1994), we set the lag truncation parameter to $m=0.75 T^{1 / 3}$. By applying modified ICSS algorithm, we were in position to detect multiple sudden changes and to implement them into the conditional variance-covariance matrix $\left(\mathbf{H}_{t}\right)$ of various BEKK-GARCH models via dummy variables. Each dummy variable is constructed as unity from structural break onwards and zero otherwise.

\subsection{Complementary methodology}

According to Roy and Roy (2017), there are two types of econometric methods of estimating volatility spillover - GARCH based and VAR based methods. In order to see are the findings from VAR based method vastly different to the ones obtained by BEKK methodology, this section uses generalized VAR methodology, i.e. the generalized spillover index of Diebold and Yilmaz (2012), to gauge the directional spillovers across national stock and exchange rate markets. Following Allen et al. (2017) and Kang and Yoon (2016), we observe a covariance stationary, first-order, two variable $\operatorname{VAR}(p)$ as:

$$
\boldsymbol{y}_{i, t}=c_{i}+\Phi_{i} A R_{i, t-1}+\varepsilon_{i, t} ; \quad \varepsilon_{i, t} \sim \text { iid },
$$

where $\boldsymbol{y}_{i, t}$ is the 21 vector $\boldsymbol{y}_{i, t}=\left[r_{i, t}, e_{i, t}\right]^{\prime}$ containing the returns of particular stock index $(r)$ and national foreign exchange rate $(e)$ of selected country $(i)$ at time $t$, while $\varepsilon_{t}$ is a series of error terms that are assumed to be serially uncorrelated. $\Phi$ is a $2 \times 2$ parameter matrix. Assuming that the above VAR process is a covariance stationary, then a moving average representation can be written as $y_{t}=\sum_{i=0}^{\infty} \mathbf{A}_{i} \varepsilon_{t}$, where $\mathbf{A}_{i}$ represents the $\mathrm{N} \times \mathrm{N}$ coefficient matrix obeying the recursion process $\mathbf{A}_{i}=\sum_{k=1}^{p} \Theta_{i} \mathbf{A}_{i-k}$ and $\mathbf{A}_{\mathbf{0}}$ is a $\mathrm{N} \times \mathrm{N}$ identity matrix with $\mathbf{A}_{i}=0$ for $i<0$. Generalized VAR framework solves the problem of Cholesky factorization in which variance decomposition becomes highly sensitive to variables ordering. Thus, using GVAR approach, the H-step-ahead forecast error variance decomposition is specified as follows:

$$
\Psi_{i j}(H)=\frac{\sigma_{j j}^{-1} \sum_{h=0}^{H-1}\left(e^{\prime}{ }_{i} A_{h} \sum e_{j}\right)^{2}}{\sum_{h=0}^{H-1}\left(e^{\prime}{ }_{i} A_{h} \sum A^{\prime}{ }_{h} e_{i}\right)},
$$


where $\Sigma$ represents the variance matrix of the vector of errors $\varepsilon$, while $\sigma_{j j}$ stands for the standard deviation of the error term of the $j$-th equation. The sum of elements in each row of the variance decomposition matrix is not equal to one, i.e. $\sum_{j=1}^{N} \Psi_{i j}(H) \neq 1$. According to Diebold and Yilmaz (2012), then each element of variance decomposition matrix is normalized by dividing them by respective row sums, and the new H-step-ahead variance decomposition looks like Equation 8:

$$
\tilde{\Psi}_{i j}(H)=\frac{\Psi_{i j}(H)}{\sum_{j=1}^{N} \Psi_{i j}(H)} .
$$

Then applies, $\sum_{j=1}^{N} \tilde{\Psi}_{i j}(H)=1$ and $\sum_{j=1}^{N} \tilde{\Psi}_{i j}(H)=N$. From Equation 8, a total volatility spillover index, $S(H)$, can be constructed as:

$$
S(H)=\frac{\sum_{i, j=1, i \neq j}^{N} \tilde{\Psi}_{i j}(H)}{\sum_{i, j=1}^{N} \tilde{\Psi}_{i j}(H)} \times 100=\frac{\sum_{i, j=1, i \neq j}^{N} \tilde{\Psi}_{i j}(H)}{N} \times 100 .
$$

The measure of the directional volatility spillovers received by market $i$ from all other markets $j$ is calculated as:

$$
S_{i .}(H)=\frac{\sum_{j=1, i \neq j}^{N} \tilde{\Psi}_{i j}(H)}{\sum_{i, j=1}^{N} \tilde{\Psi}_{i j}(H)} \times 100=\frac{\sum_{j=1, i \neq j}^{N} \tilde{\Psi}_{i j}(H)}{N} \times 100 .
$$

Similarly, directional volatility spillovers transmitted by market $i$ to all other markets $j$ is as follows:

$$
S_{. i}(H)=\frac{\sum_{j=1, i \neq j}^{N} \tilde{\Psi}_{j i}(H)}{\sum_{i, j=1}^{N} \tilde{\Psi}_{j i}(H)} \times 100=\frac{\sum_{j=1, i \neq j}^{N} \tilde{\Psi}_{j i}(H)}{N} \times 100 .
$$

\section{Dataset Statistics and Detection of Multiple Structural Breaks}

The dataset in this study includes the daily closing log returns of seven emerging equity indices, namely: PX (the Czech Republic), WIG (Poland), BUX (Hungary), RTS (Russia), XU100 (Turkey), SENSEX (India) and KOSPI (South Korea) as well as corresponding currencies - koruna, zloty, forint, ruble, lira, rupee and won. In addition, we analyse American S\&P500 index and USD, which serve as a benchmark. The observed time period ranges from 3 January 2001 to 31 July 2016 for all asset-return series and they were collected from Datastream. All nominal exchange rates are perceived vis-à-vis euro except Czech koruna, because Czech national bank imposed upper bond on $27 \mathrm{CZK} / \mathrm{EUR}$ in November 2014 to prevent further depreciation of Czech currency. Thus, we observe koruna vis-à-vis USD, where such constraint did not exist. All selected stock indices are used in local currency terms base on daily closing prices. All pairs of stock indices and corresponding exchange 
rates are synchronized according to the existing observations due to unavailability of some data, which is caused by the different non-working days in the national financial markets. The succinct descriptive statistics in Table 1 presents first four moments, Jarque-Bera coefficients of normality, Ljung-Box Q-statistics and unit root tests of assets' unconditional distributions.

Table 1 | Descriptive Statistics and Unit Root Tests of Selected Indices and Exchange Rates

\begin{tabular}{|c|c|c|c|c|c|c|c|c|c|}
\hline & Mean & St. dev. & Skew. & Kurtosis & JB & LB(Q) & LB(Q2) & DF-GLS & KPSS \\
\hline \multicolumn{10}{|c|}{ Indices } \\
\hline PX & 0.016 & 1.420 & -0.501 & 16.178 & 28,362 & 0.000 & 0.000 & -6.151 & 0.404 \\
\hline WIG & 0.025 & 1.250 & -0.344 & 6.164 & 1,704 & 0.000 & 0.000 & -11.521 & 0.161 \\
\hline BUX & 0.033 & 1.548 & -0.107 & 9.301 & 6,422 & 0.000 & 0.000 & -10.637 & 0.122 \\
\hline RTS & 0.051 & 2.202 & -0.370 & 12.091 & 13,179 & 0.000 & 0.000 & -2.718 & 0.608 \\
\hline XU100 & 0.051 & 2.085 & -0.347 & 9.885 & 7,656 & 0.000 & 0.000 & -5.914 & 0.098 \\
\hline SENSEX & 0.050 & 1.499 & -0.091 & 11.063 & 10,369 & 0.000 & 0.000 & -13.668 & 0.092 \\
\hline KOSPI & 0.035 & 1.468 & -0.515 & 9.384 & 6,644 & 0.568 & 0.000 & -60.228 & 0.141 \\
\hline S\&P500 & 0.013 & 1.253 & -0.203 & 11.548 & 11,839 & 0.000 & 0.000 & -2.363 & 0.198 \\
\hline \multicolumn{10}{|c|}{ Exchange rates } \\
\hline Koruna & -0.013 & 0.760 & 0.202 & 6.145 & 1,631 & 0.000 & 0.000 & -5.019 & 0.278 \\
\hline Zloty & 0.003 & 0.598 & 0.442 & 8.832 & 5,656 & 0.000 & 0.000 & -5.849 & 0.041 \\
\hline Forint & 0.004 & 0.589 & 0.679 & 10.982 & 10,594 & 0.000 & 0.000 & -46.161 & 0.057 \\
\hline Ruble & 0.026 & 0.863 & 2.689 & 98.805 & $1,458,655$ & 0.000 & 0.000 & -6.714 & 0.124 \\
\hline Lira & 0.030 & 1.046 & 0.876 & 21.247 & 53,735 & 0.000 & 0.000 & -15.990 & 0.046 \\
\hline Rupee & 0.014 & 0.646 & -0.037 & 5.773 & 1,226 & 0.494 & 0.000 & -5.235 & 0.056 \\
\hline Won & 0.001 & 0.772 & 0.027 & 14.323 & 20,373 & 0.000 & 0.000 & -9.195 & 0.160 \\
\hline USD & 0.004 & 0.639 & -0.141 & 5.823 & 1,301 & 0.027 & 0.000 & -5.469 & 0.323 \\
\hline
\end{tabular}

Notes: JB denotes the value of the Jarque-Bera test for normality, $L B(Q)$ and $L B\left(Q^{2}\right)$ label $p$-values of the Ljung-Box Q-statistics for level and squared residuals for 20 lags. Assuming the absence of the trend, the $1 \%$ and $5 \%$ critical values for the DF-GLS test (modified Dickey-Fuller test) with ten lags are -2.566 and -1.941 , respectively. $1 \%$ and $5 \%$ critical values for the KPSS test are 0.739 and 0.463 , respectively.

Source: Authors' calculation

Results in Table 1 show non-normal behaviour for all selected equity returns as well as currencies, which is substantiated by the notably pronounced leptokurtosis in all markets. High values of JB test verify non-normal characteristics, which justifies the use of standard Student $t$-distribution in all BEKK-GARCH models. LB(Q) test statistics for level and squared returns check for the presence of autocorrelation and heteroscedasticity. 
As can be seen, a white noise process is present only in Korean KOSPI index and Indian currency - rupee, while all other indices and currencies have serial correlation in residuals, which is an indication that $\mathrm{AR}(1)$ mean specification might be suitable. On the other hand, $\mathrm{LB}\left(\mathrm{Q}^{2}\right)$ test implies the presence of time-varying variance with an $\mathrm{ARCH}$ pattern in all series, indicating that GARCH parameterization might be appropriate. DF-GLS test and KPSS test are applied in order to discard the possibility of spurious regressions. DF-GLS test finds that all selected time series do not contain unit roots, while KPSS test confirms presence of stationarity in all series and this test is more appropriate in the case of near unit root processes. Table 2 provides the number of break points, and Figure 1 presents log returns of selected series with depicted structural breaks.

Table 2 | Number of Breaks Detected in the Stock and Currency Markets

\begin{tabular}{|l|c|l|c|}
\hline Indices & $\begin{array}{c}\text { Numbers } \\
\text { of breaks }\end{array}$ & Currencies & $\begin{array}{c}\text { Numbers } \\
\text { of breaks }\end{array}$ \\
\hline PX & 3 & Koruna & 2 \\
\hline WIG & 3 & Zloty & 6 \\
\hline BUX & 2 & Forint & 3 \\
\hline RTS & 2 & Ruble & 2 \\
\hline XU100 & 3 & Lira & 4 \\
\hline SENSEX & 3 & Rupee & 6 \\
\hline KOSPI & 5 & Won & 5 \\
\hline S\&P500 & 6 & USD & 4 \\
\hline
\end{tabular}

Source: Authors' calculation 


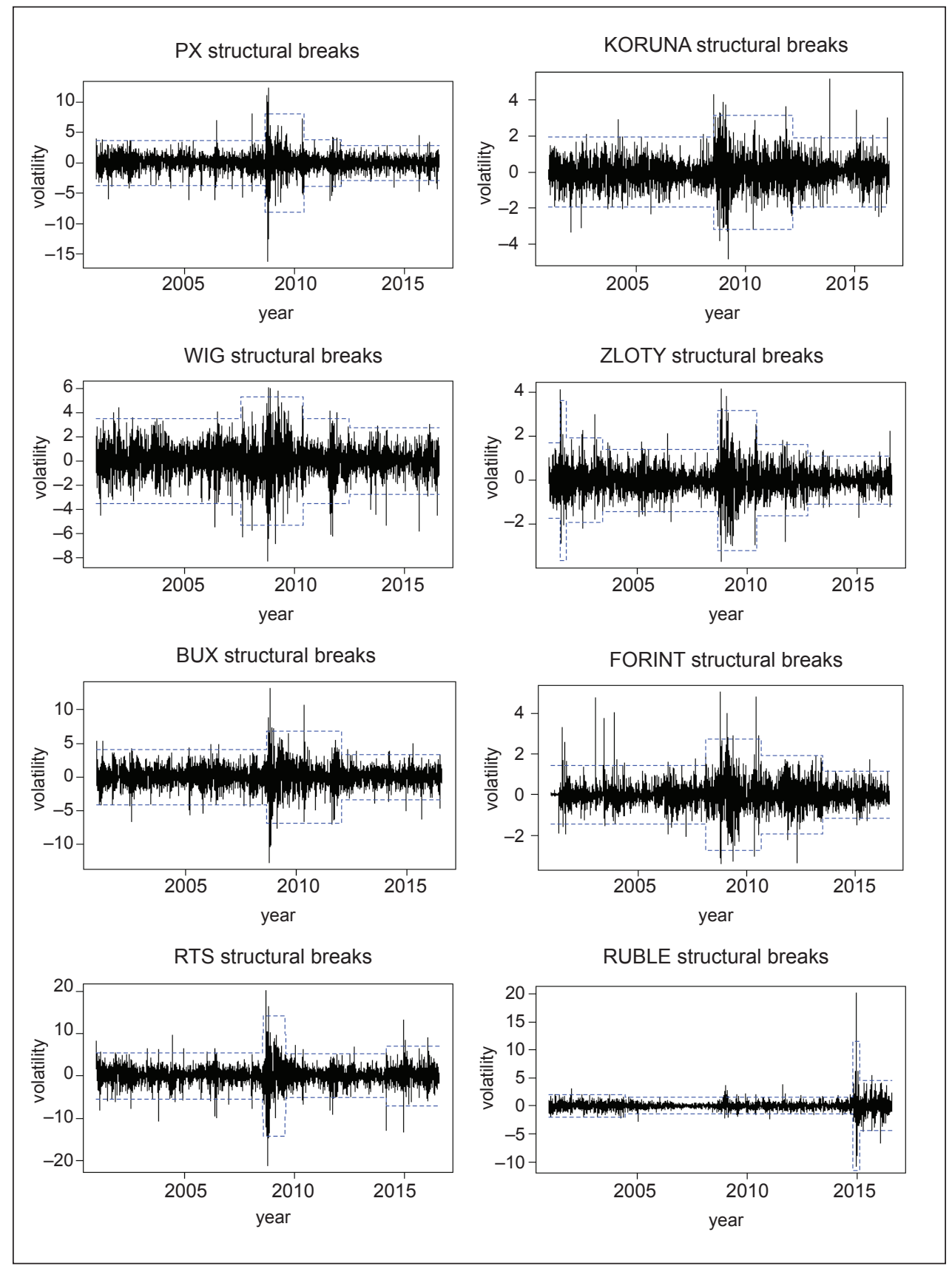


Figure 1 | Continuation

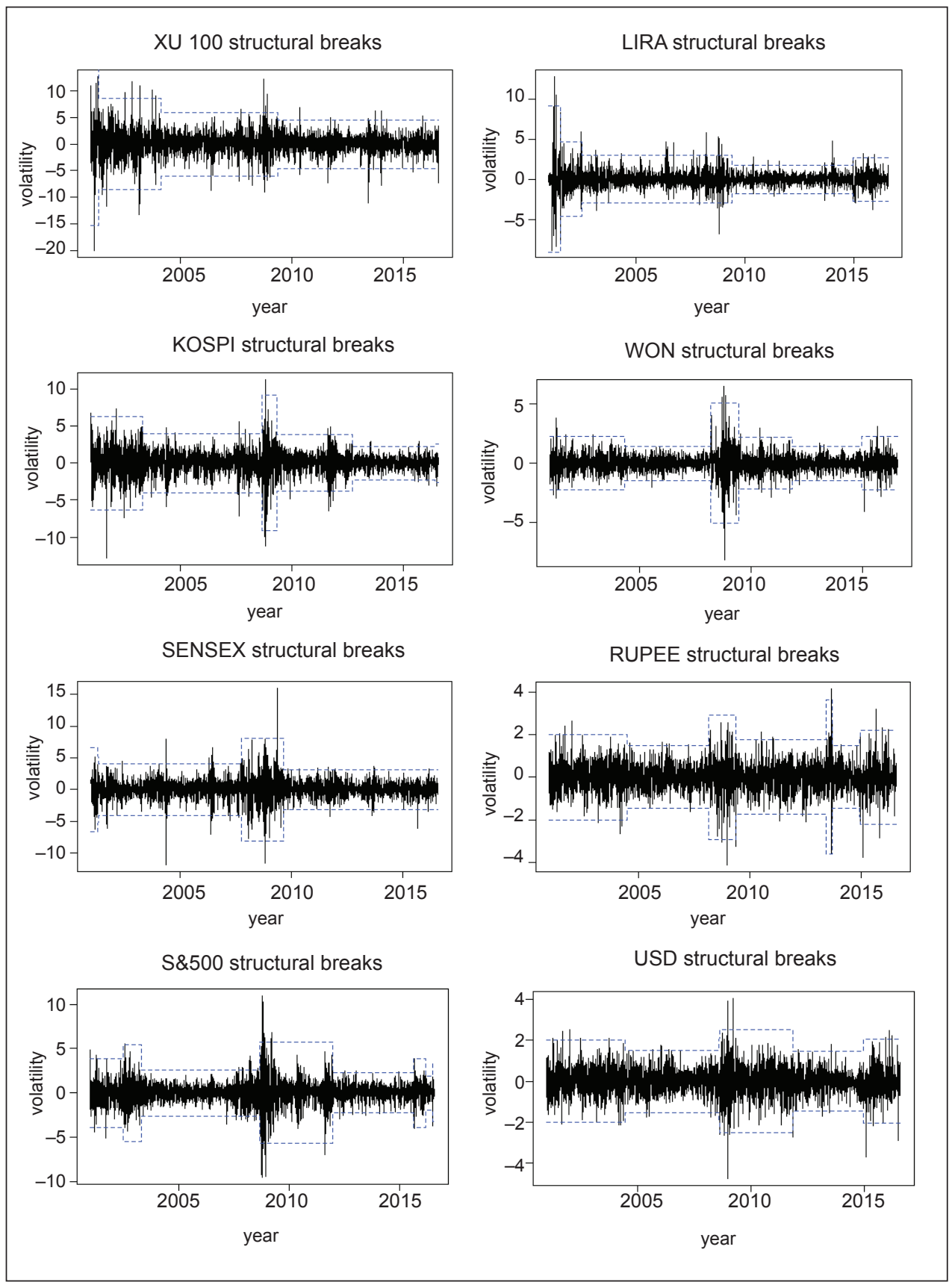

Note: Dotted lines denote bands of \pm 3 standard deviations, where change points are estimated by the modified ICSS algorithm.

Source: Authors' calculation 


\section{Research Results}

\subsection{BEKK-GARCH estimates}

In the first part of this section we examine the interrelationship between stocks and exchange rates in selected emerging economies from the stances of the two theoretical approaches - flow oriented versus portfolio balanced. Furthermore, we present the results of bidirectional shock spillover effect between major financial markets. Tables 4 and 5 contain estimated parameters of three types of BEKK-GARCH models as well as diagnostic test and information criteria. According to the test results in Tables 4 and 5, all models have very good statistical properties, since all $\mathrm{LB}(\mathrm{Q})$ and $\mathrm{LB}\left(\mathrm{Q}^{2}\right)$ tests reject the presence of serial correlation and heteroscedasticity in the models' residuals. Therefore, we can rely on the trustworthiness of the conditional correlations results as well as conditional variance parameters. Moreover, it should be noted that, according to log likelihood function and three information criteria, in six out of eight instances the best performing model is asymmetric BEKK-GARCH with structural breaks. Only in cases of Russia and the USA, the best performing models are asymmetric BEKK-GARCH without breaks according to three criteria. These findings justify the usage of three different types of BEKK models in the process of empirical fitting.

Figure 2 contains plotted conditional correlations of the optimal BEKK-GARCH models per countries, and Table 3 presents their average values as well as export level in \% of GDP in 2015. Visual inspection of the dynamic correlations' plots could answer the question whether the flow oriented theory or the portfolio balanced approach explains mutual nexus between two financial markets. With reference to this, all emerging economies have predominantly negative conditional correlation coefficients, which is in accordance with the portfolio balanced approach. Only in the case of Russia and the Czech Republic, these parameters are close to zero and thus a definite contention cannot be made. As for Russia, these parameters mostly had positive values until late 2008, but in this period Bank of Russia pursued tight exchange rate management, so these results may not be credible. After that year, dynamic correlations in Russia have been predominantly in line with the portfolio balanced theory. On the other hand, koruna/USD had not such constraints so other explanation have to be offered. By all accounts, Czech dynamic correlation did not comply predominantly with either flow oriented theory or the portfolio balanced approach. The reasons could be due to the fact that currency depreciation can affect stock prices in either way. In other words, export oriented firms which gain international competitiveness and thus export more, are expected to make more profit and enjoy an increase in their stock prices. On the other hand, domestic firms that are import oriented will face an increase in production cost and a decline in their profit margin and consequently their stock prices will fall. As can be seen in Table 3, Czech economy is rather export oriented and thus most likely Czech stocks were affected according to flow oriented theory before World Financial Crisis (WFC). However, the financial factor, i.e. capital inflows (outflows) was probably more pronounced after WFC and hence dynamic correlation was more in line with the portfolio balanced approach. 
Table 3 | Average Conditional Correlation and Level of Export in 2015 per Countries

\begin{tabular}{|l|r|r|r|r|r|r|r|r|}
\hline & $\begin{array}{c}\text { Czech } \\
\text { Republic }\end{array}$ & Poland & Hungary & Russia & Turkey & India & $\begin{array}{c}\text { South } \\
\text { Korea }\end{array}$ & USA \\
\hline Average $\rho^{*}$ & -0.086 & -0.275 & -0.274 & -0.048 & -0.345 & -0.115 & -0.211 & 0.078 \\
\hline Export in \% of GDP $^{* *}$ & 83.0 & 49.6 & 90.7 & 29.5 & 28.0 & 19.9 & 45.9 & 12.6 \\
\hline
\end{tabular}

Source: *Authors' calculation

** http://data.worldbank.org/indicator/NE.EXP.GNFS.ZS?page $=1$

Dynamic correlations outlook of all other emerging markets suggests that capital flows primarily determine the connection between two financial markets, since their average $\rho s$ are predominantly negative. Such results are expected, since vast capital amounts (many of which are short-term portfolio investments) enter fast growing emerging economies every year, with sole purpose to gain returns and leave the country soon after. From that aspect, expected national currency appreciation would most likely cause capital inflow and the rise of stocks value, because appreciation provides additional gain to investors when investment yields are expressed in some solid currency, while depreciation causes the opposite effect. According to Table 3, the strongest link is present in Turkey and Poland. Hungary and South Korea follow.

On the other hand, the dynamic nexus in the USA is completely different, i.e. conditional correlation parameters are much in line with flow oriented theory, since its average rho is positive. It is evident that the USA conditional correlations are predominantly positive during the tranquil periods, while only in the times of increased market's stress, which is usually followed by the enhanced capital movement (e.g. Iraqi war, WFC, Ukrainian crisis) these parameters have negative values, which is in line with the portfolio balanced theory. In other words, the US investors are not afraid of the currency depreciation because their revenues are already expressed in solid currency. In cases of developed countries, exchange rate fluctuations would probably influence their international competitiveness and that will eventually reflect to export and the values of their stock prices, which supports the flow oriented theory.

After determining the nature of the relationship between stocks and exchange rates, in the following we present the spillover results and explain how shocks transfer between the markets. Some parameters in Tables 4 and 5 have negative sign, but it should be said that parameters in BEKK model are shown in quadratic form, so the signs of the coefficients are irrelevant and parameters' estimates should be viewed as absolute values.

Tables 4 and 5 contain estimates of three different BEKK-GARCH models, and in order to avoid excessive information, we comment only on parameter estimates of the best fitting models in the following text. It was previously said that for Russia and the USA the asymmetric BEKK-GARCH model is optimal, while for all other countries the best performing model is asymmetric BEKK-GARCH with breaks. We also test the assertions outlined in the introduction regarding the justification and necessity of breaks insertion in the GARCH models. 


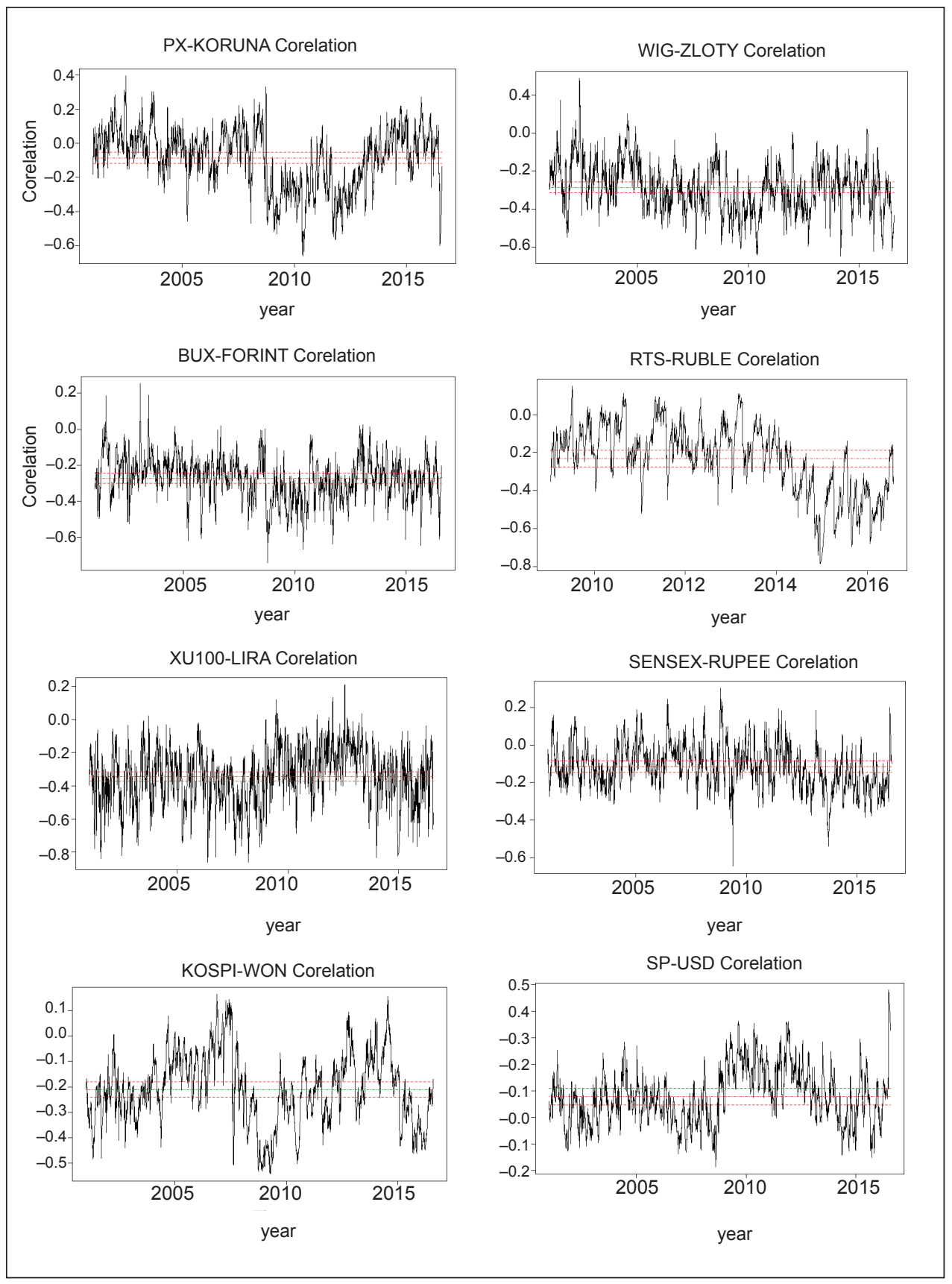

Note: Upper and lower dashed lines indicate confidence bands at $95 \%$.

Source: Authors' calculation 


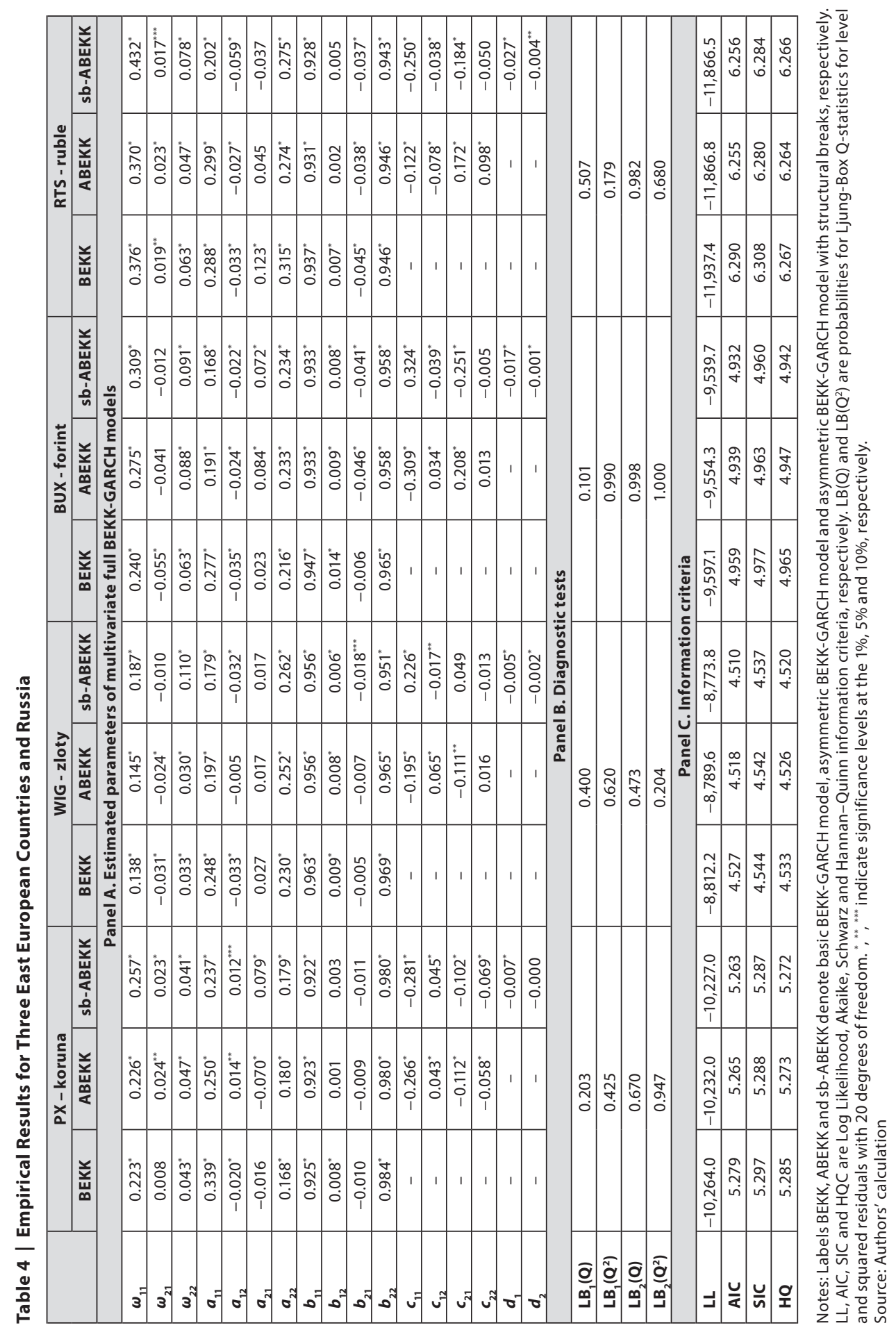




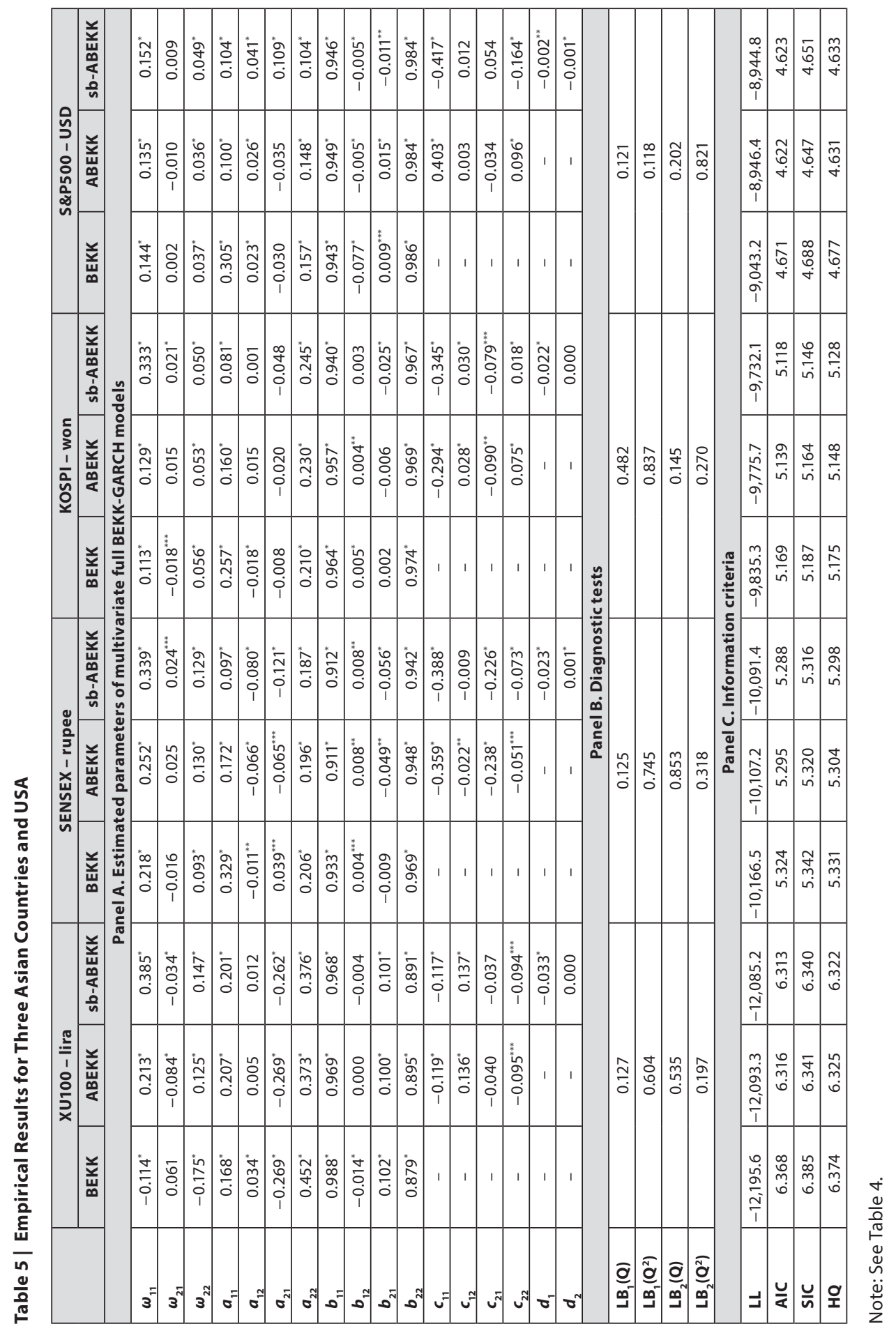


It can be noted that, in most countries, the shocks originated in the exchange rate markets $\left(a_{22}\right)$ have the greater effect on its own conditional variance in comparison with the level of own shock-effect in the stock markets $\left(a_{11}\right)$. The only exceptions are the Czech Republic and Russia, where its own-shock effect in the stock market is slightly stronger in regards to its own-shock effect in the exchange rate market. Statistically significant $b_{11}$ and $b_{22}$ parameters gauge the effect of past volatility of a market on its conditional variance and the magnitudes of these estimates are close to one, which indicates a high degree of volatility persistence. However, it is interesting to notice that in some exchange rate markets (zloty, ruble, lira, rupee and won) values of $b_{22}$ parameters are lower in the models with breaks than in the models without breaks. It also applies for some stock markets (RTS, XU100, SENSEX and KOSPI) but is less conspicuous. This finding confirms the contention of Hillebrand (2005) and Kramer and Azamo (2007) who asserted that volatility persistence might be exaggerated if deterministic regime shifts are ignored in the GARCH models. The asymmetric responses of a market to its own past negative shocks or 'bad news' are visible in the diagonal $c_{11}$ and $c_{22}$ parameters. It is obvious in all countries that stock markets have a more evident response to its own negative shocks than exchange rate markets. The highest asymmetric reaction is documented in Indian and the US stock market, while the lowest asymmetric response has Turkish stock market. Also, it should be mentioned that asymmetric effects are slightly changed when dummy variables enter BEKK-GARCH models, which is in line with Miralles-Marcelo et al. (2008), who claim that asymmetric effect in GARCH framework could be biased if structural breaks are not taken into account.

The off-diagonal parameters of the matrices $\mathbf{A}, \mathbf{B}$ and $\mathbf{C}$ gauge the transmission effect across markets. Off-diagonal parameters $a_{12}$ and $a_{21}$ show the magnitude of the average shock spillover effect from stock market to exchange rate market and vice-versa. Observing only optimal models, all spillover parameters have relatively low values, while the only exception is $a_{21}$ coefficient which measures shock transmission from Turkish lira toward XU100 index $\left(a_{21}=-0.262\right)$. Also, it can be noticed that in most emerging countries the shock transmission magnitude from exchange rate market towards stock market is much more intense than the reverse effect is. This finding is in line with studies of Živkov et al. (2015) and Fedorova and Saleem (2010). It is particularly evident in the cases of the Czech Republic, Hungary, Turkey and India. This scenario can also be found in the US market. For Poland and Russia the opposite effect applies, since $a_{21}$ parameters are not statistically significant, while in South Korea neither $a_{12}$ nor $a_{21}$ is significant, which indicates that shock spillover effect does not exist. Besides, it can be seen that in some markets the spillover effect is significantly different in models with and without breaks (e.g. PX, koruna, WIG, forint, RTS, SENSEX, rupee and USD). These results speak in favour of Ewing and Malik (2005), Huang (2012) and Jung and Maderitsch (2014) who claimed that spillover effect could be biased if structural shifts are not recognized in the models. On the other hand, the volatility spillover effect is much more modest in regard to the shock transmission effect in all countries, but the overall pattern remains, i.e. the volatility spillover effect from exchange rate market towards stock market is much more pronounced 
than other way around. The transmission of 'bad news' across markets is depicted via $c_{12}$ and $c_{21}$ coefficients. For instance, in cases of the Czech Republic, Hungary, Russia, India and South Korea significant 'bad news' spillover is much more intense from exchange rate markets to stock market, but in Poland and Turkey 'bad news' spillover is stronger from the opposite direction. In the US markets 'bad news' spillover effect is not found. Finally, it should be said that $d_{1}$ and $d_{2}$ parameters which stand in front of dummy variables are highly statistically significant in most cases, providing a vindication for dummy variables placement in the asymmetric BEKK-GARCH models.

The results of the BEKK-GARCH models suggest that, in general, national currencies suffer significantly lower impacts from stock markets in comparison with the impacts that endure stock markets from exchange rate markets. These findings lead to the conclusion that all emerging economies pay attention vigilantly on the exchange rate stability, since the exchange rate is one of the key fundamentals that affect entire economic system, directly or indirectly. On the other hand, stock markets are much more subject to the demand and supply forces, thus the shocks from the other markets have more forceful impact on stock markets.

\subsection{International spillover effects between financial markets - the case of Visegrad group}

Interesting finding would be to see whether the spillovers are actually a common phenomenon that occurs even between financial markets of different countries. Therefore, we analyse a spillover effects between countries of Visegrad group and Table 6 contain results of estimated spillover parameters $a$ and $b$. In that process, we employ three trivariate BEKKGARCH models that include two stock markets and one currency market, i.e. BUX-PXzloty, BUX-WIG-koruna and PX-WIG-forint. Since our focus of interest is not spillover between two stock markets, we do not comment $a_{12}, a_{21}, b_{12}, b_{21}$ parameters.

As can be seen, the values of spillover parameters are heterogeneous and relatively low, as in cases of the bivariate BEKK-GARCH models. For instance, shocks from Polish currency market do not affect Hungarian BUX index and Czech PX index, because $a_{31}$ and $a_{32}$ parameters are insignificant. On the other hand, BUX and PX indices have shock and volatily affect on zloty, but at very low magnitude $\left(a_{13}=-0.033, b_{13}=0.007, a_{23}=-0.015\right.$, $\left.b_{23}=0.011\right)$. Czech koruna, has no influence on BUX and WIG whatsoever, while slightly significant effect is noticed from WIG index toward koruna $\left(a_{23}=-0.017\right)$. The results are somewhat surprising at third combination in the sence that we find statisticaly significant spillover effect between two stock indices and Hungarian currency at relatively high values. As it turned out, according to the trivariate BEKK model, Hungarian forint has bigger shock and volatility impact on PX and WIG indices comparing to the impact of national currencies (koruna and zloty) on corresponding indices (PX and WIG), as suggested by the bivariate BEKK models. In other words, forint's shock and volatility spillovers toward PX are on average $a_{31}=-0.122, b_{31}=0.041$, while forint's effects on WIG are $a_{32}=-0.080$, $b_{32}=0.043$. The possible explanation could lie in the fact that in spite of relatively low 
standard deviation of forint, Hungarian currency has the largest kurtosis of all Visegrad countries, as Table 1 suggests and Figure 1 depicts, which means that forint had the largest number of unexpected "derailments". These events could affect Czech and Polish exporters, which would be eventually reflected on the Czech and Polish indices. According to globalEDGE site ${ }^{1}$, Hungary is the eighth largest export destination for the Czech Republic and the tenth largest export destination for Poland, with exporting volumes of 4.7 and 5.2 billion of dollars, respectively. Therefore, shock and volatility spillover effect between two largest financial markets are not necessarily constrained by national borders, but could be an international phenomenon as well.

Table 6 | Results of Spillover Parameters of Trivariate BEKK-GARCH Model

\begin{tabular}{|l|c|c|c|}
\hline & BUX-PX-zloty & BUX-WIG-koruna & PX-WIG-forint \\
\hline $\boldsymbol{a}_{\mathbf{1 2}}$ & $0.050^{*}$ & $0.022^{*}$ & 0.021 \\
\hline $\boldsymbol{a}_{\mathbf{2 1}}$ & $0.091^{*}$ & $0.090^{*}$ & $0.084^{*}$ \\
\hline $\boldsymbol{b}_{\mathbf{1 2}}$ & $-0.016^{* *}$ & $-0.013^{*}$ & -0.005 \\
\hline $\boldsymbol{b}_{\mathbf{2 1}}$ & $-0.025^{*}$ & -0.006 & -0.009 \\
\hline $\boldsymbol{a}_{\mathbf{1 3}}$ & $-0.033^{*}$ & -0.007 & $-0.024^{*}$ \\
\hline $\boldsymbol{a}_{\mathbf{3 1}}$ & 0.052 & -0.015 & $0.012^{*}$ \\
\hline $\boldsymbol{b}_{\mathbf{1 3}}$ & $0.007^{*}$ & 0.001 & $0.041^{*}$ \\
\hline $\boldsymbol{b}_{\mathbf{3 1}}$ & -0.009 & 0.013 & 0.011 \\
\hline $\boldsymbol{a}_{\mathbf{2 3}}$ & $-0.015^{* *}$ & $-0.017^{* *}$ & $-0.080^{*}$ \\
\hline $\boldsymbol{a}_{\mathbf{3 2}}$ & -0.007 & -0.001 & $-0.012^{*}$ \\
\hline $\boldsymbol{b}_{\mathbf{2 3}}$ & $-0.011^{*}$ & $0.005^{* * *}$ & $0.043^{*}$ \\
\hline $\boldsymbol{b}_{\mathbf{3 2}}$ & -0.002 & \\
\hline
\end{tabular}

Notes: ${ }^{*},{ }^{*},{ }^{* * *}$ indicate significance levels at the $1 \%, 5 \%$ and $10 \%$, respectively.

Source: Authors' calculation

\subsection{VAR based spillover results}

This section explains the findings of the generalized VAR (GVAR) volatility spillover methodology of Diebold and Yilmaz (2012), and Table 7 sums these results. Table 7 contains eight subdivisions referring to eight selected pairs of stocks and exchange rate markets. The rows labelled as DTO (directional to others) exclude the main diagonal elements and report only the spillovers transmitted to particular stock and exchange rate volatility. Similarly, the columns labelled as DFO (directional from others) also exclude

1 https://globaledge.msu.edu/countries/ 
the main diagonal elements and report only the spillovers received by particular stock and exchange rate volatility. The total volatility spillover index appears in the lower right corner of the spillover table, and it is calculated as ratio between the off-diagonal column sum (or row sum) and the column sum including diagonals (or row sum including diagonals), expressed as a percentage.

Table 7| VAR Based Volatility Spillover Results between Index and Foreign Exchange

\begin{tabular}{|c|c|c|c|c|c|c|c|}
\hline & PX & Koruna & DFO & & WIG & Zloty & DFO \\
\hline PX & 98.39 & 1.61 & 1.6 & WIG & 98.35 & 1.65 & 1.7 \\
\hline Koruna & 1.39 & 98.61 & 1.4 & Zloty & 1.52 & 98.48 & 1.5 \\
\hline DTO & 1.4 & 1.6 & 3.0 & DTO & 1.5 & 1.7 & 3.2 \\
\hline \multirow[t]{2}{*}{ DIO } & 99.8 & 100.2 & $1.5 \%$ & DIO & 99.9 & 100.1 & $1.6 \%$ \\
\hline & BUX & Forint & DFO & & RTS & Ruble & DFO \\
\hline BUX & 98.96 & 1.04 & 1.0 & RTS & 97.80 & 2.20 & 2.2 \\
\hline Forint & 1.15 & 98.85 & 1.2 & Ruble & 2.04 & 97.96 & 2.0 \\
\hline TO & 1.2 & 1.0 & 2.2 & DTO & 2.0 & 2.2 & 4.2 \\
\hline \multirow[t]{2}{*}{ DIO } & 100.1 & 99.9 & $1.1 \%$ & DIO & 99.8 & 100.2 & $2.1 \%$ \\
\hline & XU100 & Lira & DFO & & SENSEX & Rupee & DFO \\
\hline XU100 & 96.19 & 3.81 & 3.8 & SENSEX & 99.46 & 0.54 & 0.5 \\
\hline Lira & 4.16 & 95.84 & 4.2 & Rupee & 0.56 & 99.44 & 0.6 \\
\hline DTO & 4.2 & 3.8 & 8.0 & DTO & 0.6 & 0.5 & 1.1 \\
\hline \multirow[t]{2}{*}{ DIO } & 100.4 & 99.6 & $4.0 \%$ & DIO & 100.0 & 100.0 & $0.5 \%$ \\
\hline & KOSPI & Won & DFO & & S\&P500 & USD & DFO \\
\hline KOSPI & 99.09 & 0.91 & 0.9 & S\&P500 & 99.36 & 0.64 & 0.6 \\
\hline Won & 0.87 & 99.13 & 0.9 & USD & 1.15 & 98.85 & 1.2 \\
\hline DTO & 0.9 & 0.9 & 1.8 & DTO & 1.2 & 0.6 & 1.8 \\
\hline DIO & 100.0 & 100.0 & $0.9 \%$ & DIO & 100.5 & 99.5 & $0.9 \%$ \\
\hline
\end{tabular}

Notes: DTO, DFO and DIO mean C, directional to others, directional from others and directional including own, respectively.

As can be seen, all off-diagonal spillover parameters are quite low, which indicates that both stock markets and exchange rate markets contribute to the corresponding volatility forecast-error variance with very low per cent. These finding are in line with the BEKKGARCH results, where we in most cases also find relatively low volatility spillover parameters. Besides, it can be noticed that both from and to spillover measures are relatively 
equable in all examined cases. However, this is not the predominant occurrence in the BEKK results, i.e. particularly significant discrepancy applies to the following examples - XU100lira $\left(b_{12}=-0.004, b_{21}=0.101^{*}\right)$, SENSEX-rupee $\left(b_{12}=0.008^{* *}, b_{21}=-0.056^{*}\right)$, RTS-ruble $\left(b_{12}=0.005, b_{21}=-0.037^{*}\right)$, and BUX-forint $\left(b_{12}=0.009^{*}, b_{21}=-0.046^{*}\right)$. In addition, VAR based methodology do not indicate convincingly that volatility spillover from exchange rate markets to stock markets are stronger than the other way around. As a matter of fact, only in three out of seven emerging market instances this is the case. In three cases the opposite applies, and as for KOSPI-won, the volatility spillover effects are even. The total volatility spillover measure in the lower right corner of Table 7 suggests that, only between $0.5 \%$ and $4 \%$ of the volatility forecast error variance comes from spillovers.

\section{Summary and Conclusion}

This paper investigates the interconnection and bidirectional shock transmission effect between stock and exchange rate markets in seven emerging countries, while the US economy is used as benchmark. Research approach comprises three types of BEKK-GARCH models, which can provide simultaneously the results of conditional correlation and the spillover effect. VAR based method serves as a complementary methodology. Conditional correlations in emerging economies are predominantly negative, which suggests that nexuses between the two markets are shaped in accordance with the portfolio balanced theory. It implies that capital flows play an important part in the determination of their mutual relationship. According to the findings, Turkey has the strongest link between the two major markets. On the other hand, conditional correlations in the US markets are overwhelmingly positive, which is in line with the flow oriented theory. It suggests that exchange rate fluctuations are likely to affect the international competitiveness of USA and its export, which is eventually reflected on the stock prices. As for the spillover effect, the BEKK results suggest that shock transmission effect is much stronger from the exchange rate market towards stock market than other way around, and this applies for all selected countries. Volatility spillover effect is also present, but with more modest intensity comparing to the shock spillover effect. These findings suggest that policymakers in emerging markets watchfully take care of exchange rate stability as one of the key prerequisites for the overall system stability. Trivariate BEKK-GARCH model between countries of Visegrad group reveals that shock and volatility spillover effects between two largest financial markets do not necessarily happen only within national borders, but can be an international phenomenon as well.

This paper can be further enriched in the following ways. Firstly, other major emerging markets with flexible exchange rate could be analysed such as Indonesia, Malesia, Brazil, Mexico, etc. Secondly, the spillover effect could be assessed by observing distinctively different time periods, i.e. before, during and after WFC.

The presented research could provide valuable information to international investors interested in emerging markets, in terms of better understanding of the interrelationship between the analysed markets. In addition, we believe that findings could help with the decisions regarding portfolio structuring and related hedging strategies. 


\section{References}

Alagidede, P., Panagiotidis, T., Zhang, X. (2011). Causal Relationship between Stock Prices and Exchange Rates. Journal of International Trade and Economic Development, 20(1), 67-86, https://doi.org/10.1080/09638199.2011.538186

Allen, D. E., McAleer, M., Powell, R. J., Singh, A. K. (2017). Volatility Spillovers from Australia's Major Trading Partners across the GFC. International Review of Economics and Finance, 47, 159-175, https://doi.org/10.1016/j.iref.2016.10.007

Bollerslev, T., Wooldridge, J. M. (1992). Quasi-Maximum Likelihood Estimation and Inference in Dynamic Models with Time-Varying Covariances. Econometric Reviews, 11(2), 143-172, https://doi.org/10.1080/07474939208800229

Caporale, G. M., Hunter, J., Ali, F. M. (2014). On the Linkages between Stock Prices and Exchange Rates: Evidence from the Banking Crisis of 2007-2010. International Review of Financial Analysis, 33, 87-103, https://doi.org/10.2139/ssrn.2248684

Carpantier, J. F., Samkharadze, B. (2013). The Asymmetric Commodity Inventory Effect on the Optimal Hedge Ratio. Journal of Futures Markets, 33(9), 868-888, https://doi. org/10.1002/fut.21566

Coudert, V., Couharde, C., Mignon, V. (2011). Exchange Rate Volatility across Financial Crises. Journal of Banking and Finance, 35(11), 3010-3018, https://doi.org/10.1016/j. jbankfin.2011.04.003

Diebold, F. X., Yilmaz, K. (2012). Better to Give than to Receive: Predictive Directional Measurement of Volatility Spillovers. International Journal of Forecasting, 28(1), 57-66, https://doi.org/10.1016/j.ijforecast.2011.02.006

Durčáková, J. (2011). Foreign Exchange Rate Regimes and Foreign Exchange Markets in Transitive Economies. Prague Economic Papers, 20(4), 309-328, https://doi. org/10.18267/j.pep.402

Engle, R. F., Kroner, K. F. (1995). Multivariate Simultaneous Generalized ARCH. Econometric Theory, 11(1), 122-150, https://doi.org/10.1017/S0266466600009063

Ewing, B. T., Malik, F. (2005). Re-Examining the Asymmetric Predictability of Conditional Variances: the Role of Sudden Changes in Variance. Journal of Banking and Finance, 29(10), 2655-2673, https://doi.org/10.1016/j.jbankfin.2004.10.002

Fedorova, E., Saleem, K. (2010) Volatility Spillovers between Stock and Currency Markets: Evidence from Emerging Eastern Europe. Finance a úvěr: Czech Journal of Economics and Finance, 60(6), 519-533.

Gannon, G., Au-Yeung, S. P. (2004). Structural Effects and Spillovers in HSIF, HIS and S\&P500 Volatility. Research in International Business and Finance, 18(3), 305-317, https://doi. org/10.1016/j.ribaf.2004.04.005

Hanuosek, J., Kočenda, E. (2011). Foreign News and Spillovers in Emerging European Stock Markets. Review of International Economics, 19(1), 170-188, https://doi. org/10.1111/j.1467-9396.2010.00939.x

Hillebrand, E. (2005). Neglecting Parameter Changes in GARCH Models. Journal of Econometrics, 129(1-2), 121-138, https://doi.org/10.1016/j.jeconom.2004.09.005

Huang, P. K. (2012). Volatility Transmission across Stock Index Futures when There Are Structural Changes in Return Variance. Applied Financial Economics, 22(19), 1603-1613, https://doi. org/10.1080/09603107.2012.669459 
Inci, A. C., Lee, B. S. (2014). Dynamic Relations between Stock Returns and Exchange Rate Changes. European Financial Management, 20(1), 71-106, https://doi. org/10.1111/j.1468-036X.2011.00621.x

Inclan, C., Tiao, G. C. (1994). Use of Cumulative Sums of Squares for Retrospective Detection of Changes of Variance. Journal of the American Statistical Association, 89(427), 913-923, https://doi.org/10.1080/01621459.1994.10476824

Jung, R. C., Maderitsch, R. (2014). Structural Breaks in Volatility Spillovers between International Financial Markets: Contagion or Mere Interdependence? Journal of Banking and Finance, 47, 331-342, https://doi.org/10.1016/j.jbankfin.2013.12.023

Kang, S. H., Cheong, C., Yoon, S. M. (2011). Structural Changes and Volatility Transmission in Crude Oil Markets. Physica A: Statistical Mechanics and its Applications, 390(23-24), 4317-4324, https://doi.org/10.1016/j.physa.2011.06.056

Kang, S. H., Yoon, S. M. (2016). Dynamic Spillovers between Shanghai and London Nonferrous Metal Futures Markets. Finance Research Letters, 19, 181-188, https://doi.org/10.1016/j. frl.2016.07.010

Kramer, W., Azamo, B. T. (2007). Structural Change and Estimated Persistence in the GARCH(1,1) Model. Economics Letters, 97(1), 17-23, https://doi.org/10.1016/j.econlet.2007.02.012

Mensi, W., Hammoudeh, S., Yoon, S. M. (2014). Structural Breaks and Long Memory in Modeling and Forecasting Volatility of Foreign Exchange Markets of Oil Exporters: The Importance of Scheduled and Unscheduled News Announcements. International Review of Economics and Finance, 30, 101-119, https://doi.org/10.1016/j.iref.2013.10.004

Mensi, W., Hammoudeh, S., Kang, S. H. (2015). Precious Metals, Cereal, Oil and Stock Market Linkages and Portfolio Risk Management: Evidence from Saudi Arabia. Economic Modelling, 51, 340-358, https://doi.org/10.1016/j.econmod.2015.08.005

Miralles-Marcelo, J. L., Quiros-Miralles, J. L., M, Miralles-Quiros, M. M. (2008). Asymmetric Variance and Spillover Effects Regime Shifts in the Spanish Stock Market. Journal of International Financial Markets, Institutions and Money, 18(1), 1-15, https://doi. org/10.1016/j.intfin.2006.05.004

Miralles-Marcelo, J. L., Quiros-Miralles, J. L., M, Miralles-Quiros, M. M. (2013). Multivariate GARCH Models and Risk Minimizing Portfolios: The Importance of Medium and Small Firms. Spanish Review of Financial Economics, 11(1), 29-38, https://doi.org/10.1016/j. srfe.2013.03.001

Newey, W. K., West, K. D. (1994). Automatic Lag Selection in Covariance Matrix Estimation. Review of Economic Studies, 61(4), 631-654, https://doi.org/10.2307/2297912

Roy, R. P., Roy, S. S. (2017). Financial Contagion and Volatility Spillover: An Exploration into Indian Commodity Derivative Market. Economic Modelling, 67, 368-380, https://doi. org/10.1016/j.econmod.2017.02.019

Tsagkanos, A., Siriopoulos, C. (2013). A Long-Run Relationship between Stock Price Index and Exchange Rate: A Structural Nonparametric Cointegrating Regression Approach. Journal of International Financial Markets, Institutions and Money, 25, 106-118, https://doi. org/10.1016/j.intfin.2013.01.008

Vivian, A., Wohar, M. E. (2012). Commodity Volatility Breaks. Journal of International Financial Markets, Institutions and Money, 22(2), 395-422, https://doi.org/10.1016/j. intfin.2011.12.003

Yau, H. Y., Nieh, C. C. (2009). Testing for Cointegration with Threshold Effect between Stock Prices and Exchange Rates in Japan and Taiwan. Japan and the World Economy, 21(3), 292-300, https://doi.org/10.1016/j.japwor.2008.09.001 
Živkov, D., Njegić, J., Milenković, I. (2015) Bidirectional Volatility Spillover Effect between the Exchange Rate and Stocks in the Presence of Structural Breaks in the Selected Eastern European Economies. Finance a úvěr: Czech Journal of Economics and Finance, 65(6), 477-498.

Živkov, D., Njegić, J., Mirović, V. (2016) Dynamic Nexus between Exchange Rate and Stock Prices in the Major East European Economies. Prague Economic Papers, 25(6), 686-705, https:// doi.org/10.18267/j.pep.591 